\title{
Compatibility of the frozen section method in histopathological specimens for female pelvic masses with results for pathology and tumor markers
}

\author{
Parisa Mokhles ${ }^{1}$, Amjad Ahmadi², Ramesh Rahehagh ${ }^{3}$, Nasrin Soofizadeh*1, Ebrahim Ghaderi ${ }^{4}$ \\ Received: 21 Aug 2017 \\ Published: 15 May 2019
}

\section{Abstract}

Background: Detection of pelvic masses is of great value for scheduling a proper treatment process and is an important factor for detection. Frozen section is a diagnostic method for the evaluation of pelvic tumors during surgery. The purpose of this study was to measure the compatibility of the frozen section method for histopathological specimens of female pelvic masses with pathologic results of tumor markers.

Methods: This retrospective study was performed on 188 female pelvic mass specimens during 2014-2016. Medical files for all patients with injury of female genital system who had undergone frozen section surgery was compared with the results of pathology and tumor marker tests. SPSS version 19 was used for statistical analysis. The results were analyzed by Kappa test.

Results: Based on the final pathology of the 188 specimens, $150(79.8 \%)$ were benign, $8(4.2 \%)$ intermediate, and $30(16 \%)$ malignant. Sensitivity, specificity, and validity of frozen section in benign tumors were calculated as follow: 96.7 Confidence Interval (CI95\% : 92.6-98.9\%), 97 (CI95\%: 84.7-99.9\%), and 96.8\%; in intermediate tumors, the respective numbers were: 71.4 (CI95\% :2996.3\%), 98.3 (CI95\%:95, 2-99\%, 7\%), and 97.3\%; and in the malignant tumors the numbers were: $96.3(\mathrm{CI} 95 \%: 81.9-99 \%), 97.4$ (CI95\% :93. 4-99.3\%), and 97.2\%. Positive and negative predictive values were calculated as follow: 99.3 (CI95\%:96.3-99.9\%) and 86.8\% (CI95\% :71.9-95.6\%) in benign tumors; 62.5 (CI95\% :24.5-91.5\%) and 98.9\% (CI95\%:96-99.9\%) in intermediate tumors; and 86.7 (CI95\%:69.3-96.2\%) and $99.3 \%$ (CI95\% :96.3-99.9\%) in malignant tumors.

Conclusion: The results of this study showed that the frozen section method has managed to keep its value and place among all diagnostic methods regarding pelvic masses to an acceptable extent. Except for the intermediate tumors, the frozen section method showed great accuracy in dealing with pelvic masses.

Keywords: Tumor, Frozen section, CA125

Conflicts of Interest: None declared

Funding: Kurdistan University of Medical Sciences and Research Deputy of Kurdistan University of Medical Sciences

*This work has been published under CC BY-NC-SA 1.0 license.

Copyright $\odot$ Iran University of Medical Sciences

Cite this article as: Mokhles $\mathrm{P}$, Ahmadi A, Rahehagh R, Soofizadeh N, Ghaderi E. Compatibility of the frozen section method in histopathological specimens for female pelvic masses with results for pathology and tumor markers. Med J Islam Repub Iran. 2019 (15 May);33:42. https://doi.org/10.47176/mjiri.33.42

\section{Introduction}

Pelvic masses comprise a large portion of female surgeries. The origin and cause of these masses could be from the gynecological, urinary, or digestive systems (1). The most prevalent pelvic mass for all age groups was related to the ovaries. Pelvic masses are important in the

Corresponding author: Dr Nasrin Soofizadeh, nsoofizadeh@hotmail.com

1. Department of Obstetrics and Gynecology, Faculty of Medicine, Kurdistan University of Medical Sciences, Sanandaj, Iran

2. Department of Microbiology, Faculty of Medicine, Kurdistan University of Medical Sciences, Sanandaj, Iran.

3. Department of Pathology, Faculty of Medicine, Kurdistan University of Medical Sciences, Sanandaj, Iran

4. Social Determinants of Health Research Center, Research Institute for Health Development, Kurdistan University of Medical Sciences, Sanandaj, Iran early diagnosis of malignant tumors of the ovaries (2). Ovarian cancer is the deadliest gynecological malignancy, the seventh malignant cancer, and the seventh prevalent cause of death due to cancer among females worldwide because the associated mortality is greater than the com-

$\uparrow$ What is "already known” in this topic:

Except for the intermediate tumors, the frozen section method has shown great accuracy in dealing with pelvic masses.

\section{$\rightarrow$ What this article adds:}

Higher precision in isolating specimens for frozen sections, especially in large masses, and cooperation of the surgeon and pathologist can enhance the value of this method. In addition, except for CA125, this method can prevent performing tumor marker tests, which are costly and are of low diagnostic value. 
bined mortalities secondary to the cervix and endometrial cancers (3). Different kinds of benign and malignant pelvic masses with different percentages appear in various age groups; therefore, early diagnosis and choosing the correct method of surgery for these kinds of masses is of high importance (1).

Early diagnosis methods for pelvic masses comprise physical examinations, ultrasonography, computed tomography (CT) scans, magnetic resonance imaging scan (MRIs), tumor markers, and microscopic and frozen section diagnoses during surgery. Definite and final diagnoses are also recorded based on permanent histological specimens (4-6). In gynecological and obstetrical diseases, providing frozen sections has been the most helpful method in determining the type and method of treatment of suspicious pelvic masses (7). Many studies have been performed to determine the value of diagnostic precision of frozen section for masses of different body organs; however, each provided relatively different results depending on the organ and tissue under study. Taskiran et al (2008) concluded that frozen section has a high sensitivity and specificity in the diagnosis of adnexal masses (8).

Wootipoon et al (2006), after studying 229 ovarian specimens, found that frozen section seems to be a useful method for the diagnosis of ovarian masses (9). The present study measures the compatibility of the frozen section method in histological specimens of female pelvic masses with the results of pathology and tumor markers.

\section{Methods}

This retrospective study was performed on 188 specimens of female pelvic masses. Samples were collected from women's ward of Beesat hospital in Sanandaj, Iran, during 2014-2016. First, file numbers for patients with pelvic masses who had undergone surgery by gynecology and obstetrics specialists were extracted. Then, a designed questionnaire was filled out based on patient data, results

\begin{tabular}{ccc} 
Table 1. Cross table for calculation of diagnostic test \\
\cline { 2 - 3 } Results of frozen section & \multicolumn{2}{c}{ Result of pathology } \\
\cline { 2 - 3 } & + & - \\
\hline+ & $\mathrm{a}$ & $\mathrm{b}$ \\
- & $\mathrm{c}$ & $\mathrm{d}$ \\
\hline
\end{tabular}

of pathology testing, results of tumor markers, and results of frozen section. After the data collection, SPSS version 19 was used to describe the frequency and means. The results were analyzed using Kappa test and important indices were calculated using the following formula: sensitivity: $a /(a+c)$, specificity: $d /(b+d)$, positive predictive value: $a /(a+b)$, and negative predictive value: $d /(c+d)(T a-$ ble 1).

\section{Results}

In this study, the mean age for the group with nonneoplastic masses was $41.8 \pm 13$ and was $57.2 \pm 12.9$ for the group with neoplastic masses. Among 188 patients, based on the final pathology, $150(79.8 \%)$ cases were benign, 8 $(4.2 \%)$ intermediate, and $30(16 \%)$ malignant. The most prevalent benign ovarian tumor was Serous Cystadenoma (32 cases, 17\%), followed by Dermoid Cyst (19 cases, 10\%), Mucinous Cystadenoma (18 cases, 9.5\%), Endometriotic Cyst (16 cases, $8.5 \%$ ), physiologic cysts, including follicular and corpus luteum cysts (15 cases, $8 \%$ ), and sex cord-stromal tumors (11 cases, 8.5\%). Among the intermediate specimens, 7 cases were Serous and one was $\mathrm{Mu}-$ cinous (Table 2).

Serous Carcinoma was the most prevalent malignant ovarian neoplasm (6 cases, 3.2\%), followed by Granulosa cell tumors ( 4 cases, $2.1 \%$ ). The most common benign uterine legions were Leiomyoma (40 cases, $21.3 \%$ ), followed by Uterine Adenomyosis ( 3 cases, $1.6 \%$ ). Also, the most prevalent malignant uterine masses were Adenocarcinoma (10 cases, 5.3\%), followed by Uterine Leiomyosarcoma (2 cases, $1.1 \%$ ) (Table 2). The sensitivity, specificity, and validity of frozen section in benign tumors (Table 3,4 )

Table 2. The frequency of different pelvic masses based on reports of frozen section method and final pathology

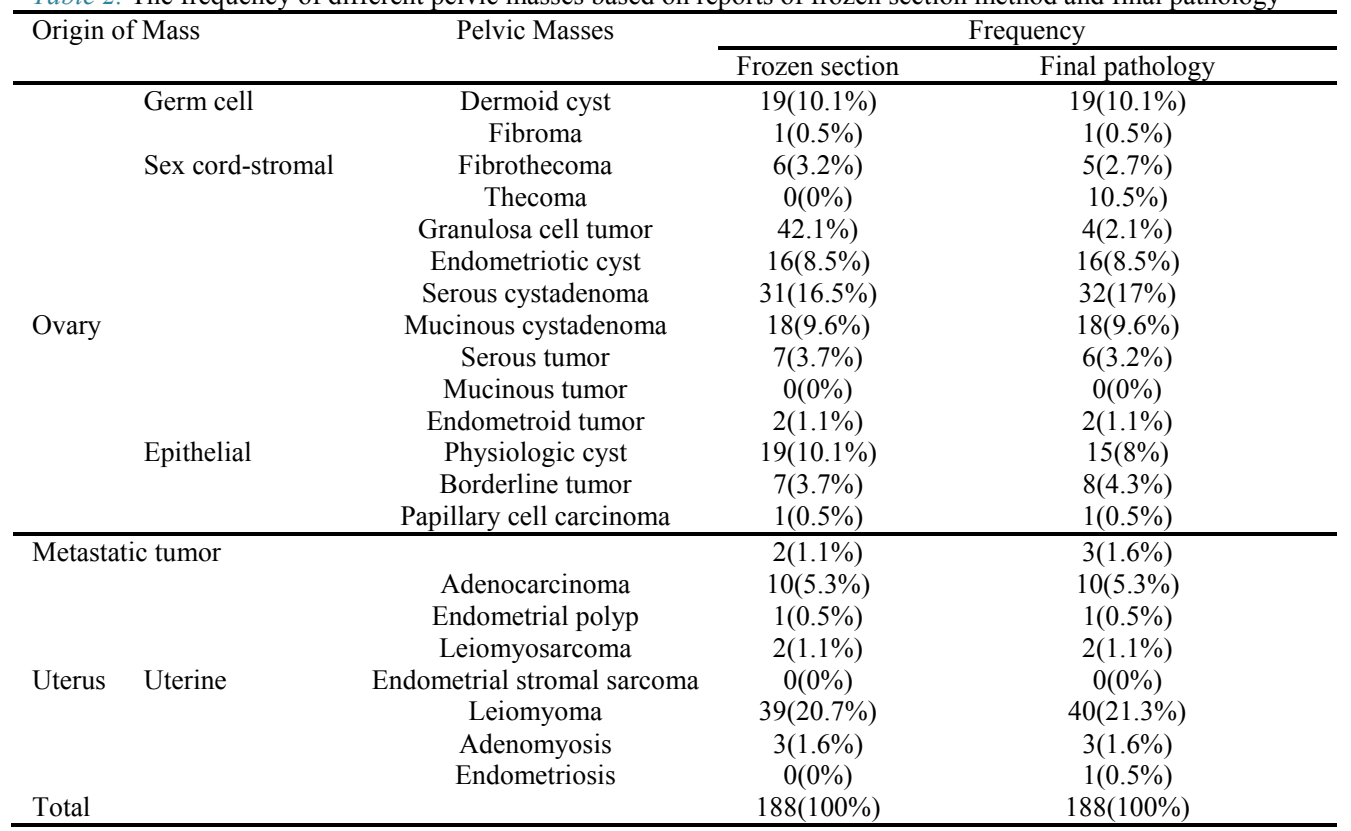


were calculated as follow: 96.7 (CI $\mathrm{CI}_{95 \%}$ : 92.6-98.9\%), 97 ( $\mathrm{CI}_{95 \%}$ :84.7-99.9\%), and 96.8\%. The sensitivity, specificity, and validity of frozen section in intermediate tumors were 71.4 ( $\mathrm{CI}_{95 \%}$ : 29-96.3\%), 98.3 ( $\mathrm{CI}_{95 \%}$ : 95.2-99.7\%), 97.3\%; and in malignant tumors: 96.3 ( $\mathrm{CI}_{95 \%}$ : $\mathrm{CI}_{95 \%}$ : 81.999\%), 97.4 ( $\mathrm{CI}_{95 \%}$ : 93.4-99.3\%), and 97.2\%. Positive and negative predictive values were calculated as follow: 99.3 (CI ${ }_{95 \%}$ : 96.3-99.9\%) and 86.8\% ( $\left.\mathrm{CI}_{95 \%}: 71.9-95.6 \%\right)$ in benign tumors; 62.5 (CI $95 \%$ : 24.5-91.5\%) and $98.9 \%$ (CI (55\%: $_{96-99.9 \%)}$ in intermediate tumors; and 86.7 (CI ${ }_{95 \%}$ : 69. 3-96.2\%) and $99.3 \%\left(\mathrm{CI}_{95 \%}: 96.3-99.9 \%\right)$ in malignant tumors. The results of this study showed that frozen section method has sensitivity of $96.3 \%\left(\mathrm{CI}_{95 \%}: 81\right.$ $9.9 \%$ ), specificity of $97.5 \%\left(\mathrm{CI}_{95 \%}: 93.8-99.3 \%\right)$, positive predictive value of $86.7 \%$ ( $\left.\mathrm{CI}_{95 \%}: 69.3-96.2 \%\right)$, negative predictive value of $99.4 \%\left(\mathrm{CI}_{95 \%}: 96.5-99.9 \%\right)$, accuracy of $97.3 \%$, and Kappa of 0.868 (Table 5).

The significant association of positive tumor markers with reports of final pathology was seen in CA125 $(\mathrm{p}<0.001)$ (Table 6).

\section{Discussion}

In gynecological and obstetrical diseases, providing frozen sections has been the most helpful method in determining the type and method of treatment of suspicious pelvic masses (7). Many studies have been performed to determine the value of diagnostic precision for frozen sections in masses of different body organs; however, each have provided relatively different results depending on the organ and tissue under study. Ilvas et al (2005), in a retrospective study on 1494 ovarian specimens, out of which 617 had gone under frozen section during 1995-2003, calculated the total value of frozen section to be $97 \%$ That 21 cases were incorrectly diagnosed by frozen section The primary reason for these errors was determined to be $\mathrm{Mu}-$ cinous and Borderline tumors. Finally, they reached the conclusion that frozen section is a reliable method in the diagnosis of ovarian masses (10). Allameh et al (2005) studied 45 tissue samples from patients during ovarian mass surgery and found that the sensitivity and specificity of diagnosis by frozen section in malignant ovarian masses were $100 \%$ and $88.5 \%$, respectively; however, for benign masses, they were $88.5 \%$ and $77 \%$, respectively. Finally, they concluded that frozen section is a reliable method for diagnosing the type of histology and ovarian masses (11). Taskiran et al (2008) conducted a study on 207 patients, which according to preliminary calculations that considered borderline histology as malignant, the diagnostic sensitivity and specificity of frozen section was $97 \%$ and $92 \%$, respectively. In the secondary analysis, in which borderline cases were considered benign, diagnostic sensitivity and specificity of this method was $100 \%$ and $98 \%$, respectively. They concluded that frozen section have high sensitivity and specificity; however, other diagnostic markers are required to enhance the diagnostic value, especially in patients with large lesions, borderline

Table 3. Agreement between the results of pathology test and reports of frozen section

\begin{tabular}{|c|c|c|c|c|}
\hline \multicolumn{3}{|c|}{ Compatibility between the report of frozen section and final pathology } & Frequency & Percent \\
\hline $\begin{array}{l}\text { Compatibility (bot } \\
\text { Not compatibility } \\
\text { Total }\end{array}$ & and both neg & & $\begin{array}{c}175 \\
13 \\
188 \\
\end{array}$ & $\begin{array}{c}93.1 \\
6.9 \\
100.0 \\
\end{array}$ \\
\hline \multicolumn{5}{|c|}{ Table 4. Comparison of frozen section and final pathology in the diagnosis of different kinds of pelvic masses } \\
\hline $\begin{array}{l}\text { Section } \\
\text { Neoplastic } \\
\text { Non neoplastic } \\
\text { Borderline } \\
\text { Total } \\
\end{array}$ & $\begin{array}{c}\text { Neoplastic } \\
26(13.8 \%) \\
3(1.6 \%) \\
1(0.5 \%) \\
30(16 \%) \\
\end{array}$ & $\begin{array}{c}\text { Non neoplastic } \\
0(0 \%) \\
149(79.3 \%) \\
1(0.5 \%) \\
150(79.8 \%) \\
\end{array}$ & $\begin{array}{c}\text { Border line } \\
1(0.5 \%) \\
2(1.1 \%) \\
5(2.7 \%) \\
8(4.2 \%) \\
\end{array}$ & $\begin{array}{c}\text { Total } \\
27(14.4 \%) \\
154(81.9 \%) \\
7(3.7 \%) \\
188(100 \%) \\
\end{array}$ \\
\hline
\end{tabular}

Table 5. Estimations of sensitivity, specificity, positive and negative predictive values, false positive and negative cases, and validity of frozen section in the diagnosis of pelvic masses

\begin{tabular}{|c|c|c|c|}
\hline Frozen Section & $\begin{array}{c}\text { Benign } \\
\text { Percent }\left(\mathrm{CI}_{95 \%}\right)\end{array}$ & $\begin{array}{c}\text { Borderline } \\
\text { Percent }\left(\mathrm{CI}_{95 \%}\right)\end{array}$ & $\begin{array}{c}\text { Malignant } \\
\text { Percent }\left(\mathrm{CI}_{95 \%}\right)\end{array}$ \\
\hline Sensitivity & $99.3 \%(96.3-99.9 \%)$ & $62.5 \%(24.5-91.5 \%)$ & $86.7 \%(69.3-96.2 \%)$ \\
\hline Specificity & $86.8 \%(71.9-95.6 \%)$ & $98.9 \%(96-99.9 \%)$ & $99.4 \%(96.5-99.9 \%)$ \\
\hline Positive predictive value & $96.7 \%(92.6-98.9 \%)$ & $71.4 \%(29-96.3 \%)$ & $96.3 \%(81-99.9 \%)$ \\
\hline Negative predictive value & $97 \%(84.7-99.9 \%)$ & $98.3 \%(95.2-99.7 \%)$ & $97.5 \%(93.8-99.3 \%)$ \\
\hline False positive & $13.2 \%(4.4-28.1)$ & $1.1 \%(0.13-3.9)$ & $0.63 \%(0.02-3.5 \%)$ \\
\hline False negative & $0.67 \%(0.02-3.7 \%)$ & $37.5 \%(8.5-75.5 \%)$ & $13.3 \%(3.7-30.7 \%)$ \\
\hline Accuracy & $96.8 \%(93.2-98.8 \%)$ & $97.3 \%(93.9-99.1 \%)$ & $97.3 \%(93.9-99.1 \%)$ \\
\hline Kappa & $89.7(81.6-97.8)$ & $65.3(36.9-93.7)$ & $89.7(80.7-98.6)$ \\
\hline \multicolumn{4}{|l|}{$\mathrm{CI}_{95 \%}: 95 \%$ Confidence interval } \\
\hline \multirow[t]{2}{*}{ Positive Tumor marker } & \multicolumn{2}{|c|}{ Report of final pathology } & $\mathrm{p}$ \\
\hline & Not Neoplastic & Neopl & \\
\hline $\mathrm{LDH}$ & $11(7 \%)$ & $5(16$ & 0.081 \\
\hline CA125 & $21(13.3 \%)$ & $12(40$ & $<0.001$ \\
\hline CEA & $3(1.9 \%)$ & $3(10$ & 0.053 \\
\hline AFP & $8(5.1 \%)$ & $1(3.3$ & 1 \\
\hline BHCG & $2(1.3 \%)$ & $0(0$ & 1 \\
\hline
\end{tabular}


tumors, and Mucinous (8). Also, Maghami et al (2010) studied 31 patients with a preliminary diagnosis of endometrial carcinoma to compare the value of diagnostic accuracy of the frozen section with final reports of their pathology. It was found that pathologic invasion to myometrium was correctly reported for $90 \%$ of patients. Finally, frozen sections were considered valuable in the detection of the early stages of low-grade tumors (12). Ah et al (2016) performed a retrospective study at Shafa International Hospital to determine the value of frozen section during surgery in the detection of different pelvic neoplasms, including ovarian tumors. The mentioned study was performed on all the patients with injury to the female genital system who had undergone frozen section surgery between January 2010 and December 2012. They concluded that frozen section had considerable value in dealing with pelvic masses with suspicious malignancy (13). Other studies have also pointed out the role of frozen sections in dealing with pelvic masses (14-18).

In the present study, out of 188 studied patients, there were 4 errors in the detection of benignity, malignancy, or borderline regarding the masses. Moreover, 2 of these cases were related to borderline tumors and the other 2 were mistakably reported as benign instead of malignant due to inadequate frozen section specimens. Because of a conservative treatment approach in these 2 cases, no errors were made. In 175 cases $(93.1 \%)$, the type of reported mass was completely compatible with frozen sections and final pathology, but they were incompatible in 13 cases $(6.9 \%)$. The most prevalent reason for incompatibility in the 4 cases was related to borderline tumors. In another 4 cases, the inadequacy of frozen section specimens and in 2 cases, incompatibility was related to Granulosa cell tumors. Contrary to other similar studies that had pointed out Mucinous tumors as a reason for error, in this study, there were only 2 erroneous cases when distinguishing between benign Mucinous cysts and Serous. Studying the results of tumor marker tests also showed that among CEA, CA125, BHCG, and LDH, there was a significant relationship only between CA125 and the report of final pathology. Therefore, to reduce the costs of the treatment for patients, only the CA125 tumor marker can be evaluated.

\section{Conclusion}

The results of this study showed that frozen section method has managed to keep its value and place among all diagnostic methods regarding pelvic masses to an acceptable extent. Higher precision in isolating specimens for frozen sections, especially in large masses, and cooperation of the surgeon and pathologist can enhance the value of this method. In addition, except for CA125, this method can prevent performing tumor marker tests, which are costly and are of low diagnostic value.

\section{Acknowledgments}

The authors would like to thank Kurdistan University of Medical Sciences and Research Deputy of Kurdistan University of Medical Sciences for financial support. Also, thanks are extended to the Gynecology ward of Beasat hospital, Sanandaj, Iran, for providing endocervical swab specimens and for data gathering.

\section{Conflict of Interests}

The authors declare that they have no competing interests.

\section{References}

1. Firoozabadi RD, Zarchi MK, Mansurian HR, Moghadam BR, Teimoori S, Naseri A. Evaluation of diagnostic value of CT scan, physical examination and ultrasound based on pathological findings in patients with pelvic masses. Asian Pac J Cancer Prev. 2011;12(7):17457.

2. Bast Jr RC, Feeney M, Lazarus H, Nadler L, Colvin R, Knapp R. Reactivity of a monoclonal antibody with human ovarian carcinoma. J Clin Invest. 1981;68(5):1331.

3. Fawzy A, Mohamed MR, Ali M, Abd M, El-Magied M, Helal A. Tissue CA125 and HE4 gene expression levels offer superior accuracy in discriminating benign from malignant pelvic masses. Asian Pac J Cancer Prev. 2016;17:323-33.

4. Tailor A, Jurkovic D, Bourne T, Collins W, Campbell S. Sonographic prediction of malignancy in adnexal masses using multivariate logistic regression analysis. Ultrasound Obstet Gynecolo. 1997;10(1):41-7.

5. Ferrazzi E, Zanetta G, Dordoni D, Berlanda N, Mezzopane R, Lissoni G. Transvaginal ultrasonographic characterization of ovarian masses: comparison of five scoring systems in a multicenter study. Ultrasound Obstet Gynecolo. 1997;10(3):192-7.

6. Jacobs IJ, Rivera H, Oram DH, Bast RC. Differential diagnosis of ovarian cancer with tumour markers CA 125, CA 15-3 and TAG 72.3.BJOG. 1993;100(12):1120-4.

7. Dadzan M, Tavassoli F. Accuracy of frozen section in borderline ovarian tumor. Rev Clin Med. 2015;2(2):72-5.

8. Taskiran C, Erdem O, Onan A, Bozkurt N, Yaman-Tunc S, Ataoglu O, et al. The role of frozen section evaluation in the diagnosis of adnexal mass. Int J Gynecol Cancer. 2008;18(2):235-40.

9. Wootipoom V, Dechsukhum C, Hanprasertpong J, Lim A. Accuracy of intraoperative frozen section in diagnosis of ovarian tumors. J Med Assoc Thai. 2006;89(5):577.

10. Ilvan S, Ramazanoglu R, Akyildiz EU, Calay Z, Bese T, Oruc N. The accuracy of frozen section (intraoperative consultation) in the diagnosis of ovarian masses. Gynecol oncolo. 2005;97(2):395-9.

11. Alameh Z, Rouh AS, Mohammadizadeh F, Alameh T. Accuracy of frozen section in diagnosis of ovarian mass in Isfahan Medical Hospital 2005.IJOGI 2006;9(2):7-10

12. Ghaemmaghami F, Aminimoghaddam S, Modares-Gilani M, Mousavi A, Khazaeipour Z, Fereidoni F. Assessment of gross examination and frozen section of uterine specimen in endometrial cancer patients. Arch Gynecol Obstet. 2010;282(6):685-9.

13. Khan AH, Mamoon N, Usman M, Laleka US ,Malik B. Accuracy of intra-operative frozen section in the diagnosis of female genital tract neoplasms. J Pak Med Assoc. 2016;66(2):143-6.

14. Hashmi AA, Naz S, Edhi MM, Faridi N, Hussain SD, Mumtaz S, et al. Accuracy of intraoperative frozen section for the evaluation of ovarian neoplasms: an institutional experience. World $\mathrm{J}$ surg oncol. 2016;14(1):91.

15. Geomini P, Bremer G, Kruitwagen R, Mol BW. Diagnostic accuracy of frozen section diagnosis of the adnexal mass: a metaanalysis. Gynecol oncol. 2005;96(1):1-9.

16. Ilker A, Aykut B, Muge H, Ibrahim HM, Ulku OB, Sener G, et al. Accuracy of intra-operative frozen section in the diagnosis of ovarian tumours. J Pak Med Assoc. 2011;61(9):856.

17. Kim JH, Kim TJ, Park YG, Lee SH, Lee CW, Song MJ, et al. Clinical analysis of intra-operative frozen section proven borderline tumors of the ovary. J gynecol oncol. 2009;20(3):176-80.

18. Ratnavelu ND, Brown AP, Mallett S, Scholten RJ, Patel A, Founta $\mathrm{C}$, et al. Intraoperative frozen section analysis for the diagnosis of early stage ovarian cancer in suspicious pelvic masses. Cochrane Database Syst Rev. 2016. 